\section{EMBRYRIDDLE}

Aeronautical University

SCHOLARLY COMMONS
Journal of Aviation/Aerospace Education \& Research

Volume 4

Number 3 JAAER Spring 1994

Article 5

Spring 1994

\title{
Flight Anxiety: Predictors and Implications for Learning
}

Paul D. Lindseth

Follow this and additional works at: https://commons.erau.edu/jaaer

\section{Scholarly Commons Citation}

Lindseth, P. D. (1994). Flight Anxiety: Predictors and Implications for Learning. Journal of Aviation/ Aerospace Education \& Research, 4(3). https://doi.org/10.15394/jaaer.1994.1131

This Article is brought to you for free and open access by the Journals at Scholarly Commons. It has been accepted for inclusion in Journal of Aviation/Aerospace Education \& Research by an authorized administrator of Scholarly Commons. For more information, please contact commons@erau.edu. 


\title{
FLIGHT ANXIETY: PREDICTORS AND IMPLICATIONS FOR LEARNING
}

\author{
Paul D. Lindseth
}

Fifty-seven randomly selected male and female student pilots enrolled in the large aviation program of a Midwestern university completed this study. The pilots were assessed within their first five flight laboratories for anxiety and associated symptoms, using a researcher-developed questionnaire and Zung's Self-Rating Anxiety-Scale. Stepwise multiple linear regressions were computed on variables of correlated symptoms for predictiveness of anxiety before flight from results on the airsickness and anxiety inventory scale and health questionnaire. Several significant predictors of pilot flight anxiety were identified. Flight anxiety and related physiological outcomes were examined, followed by an analysis of the implications of flight anxiety for learning and career aspirations.

\section{INTRODUCTION}

Anxiety associated with flight has been reported throughout aviation history (Strongin, 1987). Strongin defined anxiety as the emotional reaction to a symbolic threat on the individual's physical or psychological welfare, whether coexisting or developing separately. Flight anxiety has been associated with airsickness, early training program elimination, and possible decreased flying safety in military pilots (Bagshaw \& Stott, 1985). Instructors of civilian student pilots may wonder if flight anxiety has an impact on these pilots.

Flight anxiety could be of concern to one's aviation career, because experts have found that anxiety overcome early in flight training may resurface later in the flying career (Strongin, 1987). With this in mind, proper initial identification of anxiety, its pre-flight indicators, and subsequent intervention may prevent further flightanxiety problems.

This manuscript presents the results of a study measuring flight anxiety and its predictors in initial civilian student pilots enrolled in a university-based professional four-year degree program.

A goal of the study was to increase understanding of flight anxiety in pilot-training situations so that improved learning environments can be achieved. By focusing on the initial pilot anxiety level in conjunction with learning styles and learning environments, greater and deeper learning could result.

\section{Anxiety and Learning}

Some stress or anxiety may be a beneficial variant to a student's performance, whereas too much stress or anxiety is detrimental to performance (Levitt, 1980).

Professional degree programs have found anxiety to be a significant confounding variable when considering learning outcomes. In a study of first-year medical students (Tooth, Tonge, \& McManus, 1989), anxiety levels did not cause poor test performance, although anxiety did correlate with poorer end-of-the-year exam results. The poorer exam scores were attributed to the use of rote learning study methods rather than to a strategic or more conceptual learning method.

Anxiety of the medical students, measured by Spielberger's State-Trait Anxiety Inventory, was the highest just before the first written exam. Correlations between anxiety measures and learning strategies showed that highly anxious students were less likely to use strategic learning $(r=-0.423, \mathrm{p}<.001)$, and more likely to develop rote learning strategies by the end of the school year $(r=0.454, \mathrm{p}<0.0001)$.

In another study of anxiety and academic performance (Seipp, 1991), a major conclusion was that improvements could be made in predictions of academic performance from anxiety if anxiety is limited to test anxiety only. The study involves a meta-analysis of 126 studies with a total sample size of 36,626 subjects.

When reviewing learning styles and approaches to 
learning, Newble and Entwistle (1986) found that a more prescriptive educational environment may inhibit or distort student learning. Flight instructors may need to be more aware not only of the anxiety levels of students' learning but of their learning styles as well, in order to adapt teaching styles to ease strategic learning.

Those who learn at a more strategic level tend to be better problem-solvers (Newble \& Entwistle, 1986). It has been found that problem-solving abilities are very beneficial for pilots in precautionary and emergency flight situations (Federal Aviation Administration, 1977).

Although not all students are consistent in their methods of knowledge acquisition, understanding how a student learns may be very important for ensuring that appropriate outcomes are achieved. Students with lower anxiety levels may learn at a deeper or more conceptual level than those students who are more anxious (Newble \& Entwistle, 1986). Identifying initial pilot anxiety levels and the indicators of those levels would allow flight instructors to adjust learning environments to more readily achieve the desired outcomes.

\section{Flying and Anxiety}

Two studies of naval flight students by Bucky and Spielberger $(1972,1973)$ revealed that those students were less anxiety-prone than their college student counterparts. Yet the naval flight students responded to the stress of the early stages of flight training with extremely high levels of state anxiety.

State anxiety refers to current levels of emotion characterized by subjective feelings, apprehension, and autonomic nervous activity. On the other hand, trait anxiety is a more enduring level of anxiety.

Because high anxiety was a factor in voluntary withdrawal from flight training, the State-Trait Inventory was found to be useful in predicting voluntary withdrawal from the flight program (Bucky \& Spielberger, 1972). Although the Anxiety-Trait Scale does not measure the amount of stress associated with a particular situation, scores on the scale have been shown to increase in situations characterized by either physical danger or psychological stress and to decrease when participants have been relaxed (Bucky \& Spielberger, 1972).

No significant differences were noted in anxiety scores related to physical qualifications, to flight and academic failures, and to personal requests to be released from pilot training. There was a relationship between state anxiety at the beginning of flight training and at the completion of flight training, with pilots higher in anxiety during the first week of training more likely to voluntarily withdraw from the program.

Students who withdrew earlier in the program had higher state anxiety levels than those who dropped out later. Bucky and Spielberger (1973) calculated that if a cutoff score of 65 or higher on the Anxiety-State Scale had been used, $19 \%$ of the dropouts would have been eliminated before initial training.

In a related study, Fox and Arnon (1988) researched the relationship between anxiety and airsickness in Israeli pilots, measured the incidence of anxiety with airsickness, and then identified anxiety levels according to several anxiety scales. Their results showed higher levels of anxiety correlated with airsickness. Through past studies, they found high levels of anxiety were associated with decreased capability to handle complexity and with difficulty in dealing with added information-processing demands.

This finding further illustrates the need for identifying flight-anxiety problems early in the flying career so that intervention may be made in the learning environment.

\section{PURPOSE OF THE STUDY}

The purpose of this study was to determine the frequency, assessed symptoms, predictors, and attrition implications of flight anxiety as experienced by initial civilian student pilots. Results of the study were analyzed for implications to aviation-education learning environments as well as to student learning styles.

\section{SAMPLE}

The sampling frame of a student pilot population fulfilling requirements for professional aviation careers was obtained. The sample consisted of 64 randomly selected male and female student pilots who were in their initial training flights before solo flight and who consented to participate in the study.

Fifty-seven subjects completed the study. The typical pilots ranged in age from 18 to 30 . The female enrollment ranged from 12 to $15 \%$ of the aviation student population for the past two years. The total 
Table 1 Correlations and Regression Analysis of Pre-flight Indicators and Pilot Flight Anxiety

\begin{tabular}{lllll}
\hline & Frequency & \multicolumn{2}{c}{ Pilot Fight Anxiety } & \\
Pre-flight indicator & & $\begin{array}{l}\text { Correlation } \\
\text { Coefficient }\end{array}$ & $\begin{array}{l}\text { Beta } \\
\text { Coefficient }\end{array}$ & $\begin{array}{l}\text { Cumulative Change } \\
\text { in } R^{2} \text { Value }\end{array}$
\end{tabular}

\begin{tabular}{lclll} 
Insomnia & 28 & $.71^{* * *}$ & $.24^{*}$ & .38 \\
Fatigue/Weakness & 17 & $.53^{* * *}$ & $.29^{* *}$ & .53 \\
Apprehension & 37 & $.52^{* * *}$ & $.24^{*}$ & .59 \\
Restlessness & 31 & $.51^{* * *}$ & $.23^{*}$ & .64 \\
Urinary Frequency & 16 & $.50^{* * *}$ & .11 & .68 \\
Tremors & 9 & $.50^{* * *}$ & .08 & .68 \\
Dyspnea & 10 & $.48^{* * *}$ & .07 & .69 \\
Face Flushing & 19 & $.47^{* * *}$ & .03 & .69 \\
Palpitations & 21 & $.40^{* * *}$ & .16 & .71 \\
\hline
\end{tabular}

$\mathrm{n}=57$

Multiple Correlation $(R)=.84, R^{2}=.71^{* * * *}$

$* \mathrm{p}=<.05$

$* * \mathrm{p}=<.01$

$* * * \mathrm{p}=<.001$

**** Significant at $\mathrm{P}=<.0001, \mathrm{~F}$ test on regression, $(\mathrm{F}=12.52)$

enrollment for all flight courses within the baccalaureate aviation program during a typical semester of study was 650 students. Total enrollment of all aviation students at this Midwestern university research site was 1,500 undergraduates.

Protocol for the study was approved by the University Institutional Review Board. The student pilots were all enrolled in an Introduction to Aviation private pilot course. A \$5 participatory incentive for each student was offered. The typical pilot was a male on flight lesson number two working toward a private pilot's license.

The subjects were assessed by a nurse researcher and research assistants immediately before and after one of their flight laboratories for anxiety and associated symptoms, using a modified Self-Rating Anxiety Status Inventory Scale tool by W.K. Zung and a researcherdeveloped questionnaire.

\section{INSTRUMENTATION}

Zung's Self-Rating Anxiety Status Inventory Scale (SAS) instrument measured 20 affective and somatic symptoms of state anxiety (Ward \& Lindeman, 1982).

The form was modified so the participant could indicate his or her own responses on this self-administered scale.

Items were judged on a fourpoint system, accounting for intensity, duration, and frequency of severity. To account for trends in answers, some items were worded somatically positive and others somatically negative. Values from 1 to 4 were assigned depending on the response, and then converted to an anxiety index score.

Validity was derived from comparison to Taylor's Manifest Anxiety Scale (TMAS). When Zung (1980) established reliability, the mean SAS index was obtained by testing patients with a diagnosis of anxiety disorder. This index was significantly higher than those of other diagnostic groups $(p=<0.05)$, while other scales were not significantly different from each other $(p=>0.05)$.

For this study the alpha reliability coefficient was $\alpha$ $=.63$. The index for the SAS was arrived at by dividing the sum value scores of the 20 questions by the maximum possible score of 80 and then multiplying this fractional score by 100 .

The researcher-developed questionnaire was a health-status assessment inventory consisting of baseline, pre-flight, and post-flight data. These data were obtained by nursing assessments of the pilots' current medication intakes, allergy histories, anthropometric measurements, blood pressures, peripheral pulses, respirations, and 
Flight Anxiety: Predictors and Implications for Learning

temperatures during the base assessment period. Pre- and post-flight assessments were also obtained for variations in the subjects' health status, including conditions that might affect any system within the body (cardiovascular, respiratory, skinintegumentary, and so on). This instrument was reviewed for content validity with criteria validated by nurses with flight-nursing backgrounds.

\section{RESULTS}

Following administration of the instruments to the subjects, frequencies were tabulated for the responses to the SAS and pre-flight health assessments. Correlation coefficients were calculated as an index of the degree with which variables were related with one another. Multiple linear regressions were performed on significant variables to make flight-anxiety predictions from pre-flight assessments. The $R^{2}$ value represents the amount of variance in anxiety accounted for by the pre-flight health assessments. The minimum level of probability chosen for statistical significance for this study was $\mathrm{p}<.05$.

\section{Predictors of Pilot Flight Anxiety}

The pre-flight indicator with the highest correlation to the dependent variable, flight anxiety, was insomnia $(r$ $=.71)$. Other pre-flight indicators that correlated significantly with flight anxiety are displayed in Table 1. Regression analysis indicated nine variables correlated significantly with flight anxiety, accounting for $71 \%$ of the variance in flight anxiety $\left(R^{2}=.71\right)$. Beta coefficients of

Table 3

Implications of Flight Anxiety to Career Aspirations

\section{Anxiety Implications}

n $\quad \%$

Number of pilots who experienced airsickness

$16 \quad 28$

Number of pilots who withdrew from aviation program

814

Mean annual attrition rate

36

$\mathrm{n}=57$ the nine pre-flight indicators are listed to show the effect of each on flight anxiety while controlling for the other pre-flight indicators in the regression equation. Table 1 shows the change in the $R^{2}$ value as each of the pre-flight indicators was added to the regression equation. The low beta coefficients for dyspnea and face flushing, along with the minimal change in the $R^{2}$ value as these two variables were added to the equation, shows dyspnea and face flushing accounted for minimal effect and little or no variance in flight anxiety.

Stepwise regression analysis was performed to identify significant predictors of flight anxiety. This analysis showed that insomnia, pre-flight fatigue/weakness, apprehension, and urinary frequency were significant predictors of flight anxiety $(p<.05)$. Restlessness was not identified as a significant predictor of flight anxiety due to intercorrelations with the significant predictors.

\section{Flight Anxiety and Physiological Outcomes During Flight}

Of the 57 pilots completing this study, four subjects scored an anxiety rating of $\geq 45$, a clinically significant anxiety disorder according to Zung (1980). The average anxiety score for all pilots in the study was 32.5 .

When correlating flight-anxiety index scores with reported postflight assessments, high anxiety 
index scores correlated with the flight physiological outcomes of nausea and airsickness (see Table 2). Of physiological concern were the significant correlations between flight anxiety and nausea $(r=.38)$, and flight anxiety and airsickness $(r=.32)$. These correlations were both at the $\mathrm{p}<.01$ level.

No other significant correlations existed between flight anxiety and correlated physiological outcomes, including blood pressures, pulses, and respiration rates.

Flight Anxiety and Career Aspirations

In analyzing the implications of flight anxiety to the career aspirations of the initial student pilots, the researchers found $14 \%(n=8)$ of the student pilots withdrew from the aviation program over a 30-month period (see Table 3).

Of the 57 pilots in this study, 16 pilots reported the physiological symptom of airsickness. Thirty-one percent $(n=5)$ of the airsick pilots have decided not to become professional aviators since the inception of this study. Of the eight pilots who withdrew from the program, $63 \%$ (n $=5$ ) experienced the physiological symptom of airsickness.

\section{DISCUSSION}

A number of interesting observations emerged following analysis. Forty-nine percent of the pilots in this study experienced insomnia within the 24 hours before their flights. Furthermore, $38 \%$ of the variance in flight anxiety was attributed to insomnia. As a result, insomnia was identified as one of four significant predictors of flight anxiety. Knowing whether or not a student pilot experienced insomnia the night before the flight would be important information to the instructor planning the day's flight laboratory.

Identifying other significant predictors of flight anxiety, namely fatigue/weakness, apprehension, and urinary frequency, would also be helpful to the flight instructor.

Finally, understanding that other pre-flight indicators such as restlessness, tremors, dyspnea, face flushing, and palpitations are related to flight anxiety in student pilots may be beneficial in planning the flight lesson. More attention could be focused on creating an environment with less anxiety to enhance learning and achieve the desired learning outcomes.
This concept of creating a low-stress learning environment (Newble \& Entwistle, 1986) is further supported by Malcolm Knowles' (1975) model of learning, where the establishment of a warm, supportive, and non-threatening climate is a prerequisite condition to achieving adult learning.

By assessing a student's physical and mental state before flight, improved learning and greater student and instructor satisfaction may result. The more information the instructor knows about his or her student, the better the instructor can be prepared for that flight laboratory and any physiological problems that may occur during flight.

A self-rating anxiety inventory used by pilots before potentially high-stress flights, such as the student's first flight, solo flights, and phase checks, could be valuable to the flight instructor conducting that particular flight lab. Identifying pre-flight indicators of high anxiety could be beneficial in promoting flight safety as well.

A retrospective survey of the student pilots in this study indicated that eight pilots of the 57 pilots completing the study dropped their career goals in aviation within 30 months of the initial assessments. While $24.3 \%$ of allied health occupations students withdrew from their education programs within one year (Gupta, 1991), only $14 \%$ of the students in this study dropped their career goals within a 30-month period. This calculates to a $6 \%$ annual attrition rate from the professional aviation career degree goal for pilots.

When considering the students who dropped aviation as a career major, the average anxiety score was 32.5. The anxiety index scores ranged from 27.5 to 38 for these eight pilots. With these moderately low anxiety scores, it does not appear that anxiety was a factor in the attrition of these students from an aviation career. However, there was a moderate correlation between anxiety to airsickness, and $63 \%$ of the students who withdrew from aviation careers experienced airsickness. IMPLICATIONS FOR LEARNING ENVIRONMENTS

Flight anxiety is a physiological condition that must be addressed not only by the student pilot and instructor, but also by administrators/deans in educational flight training organizations. Considering that five out of eight students $(63 \%)$ in this study who discontinued their 
professional aviation careers experienced airsickness, the incidence of airsickness may have been a contributing factor for students dropping out of pilot training.

In a similar study, Tucker and Reinhardt (1967) reported that $21 \%$ of a sample of naval pilots experiencing airsickness within the first five flights did not complete naval flight training. Tucker and Reinhardt also found that anxious student pilots have a higher incidence of airsickness than the non-anxious students.

Anxiety is a concern for learners in aviation-related professional academic programs as well as in programs such as medicine and nursing. Garcia-Otero and Teddlie (1992) found that nurse anesthesia students who were aware of their learning styles before learning experiences demonstrated less anxiety than those who did not know their typical learning styles.

Knowledge of learning styles also improved clinical performance. Nurse anesthesia students require extensive clinical learning experiences to master practice skills, just as student pilots are required to fly numerous hours in mastering piloting skills.

Knowledge within these professional programs is gained or applied in anxiety-producing situations where life and death may be stake. Understanding the students' learning styles could greatly reduce anxiety levels, thereby promoting optimal learning conditions for the learners, whether they are student pilots or nursing anesthesia students. Furthermore, it has been suggested that teaching strategies should be modified to account for in- dividual student needs to accommodate the higher anxiety levels to promote deeper learning.

\section{CONCLUSION AND RECOMMENDATIONS FOR FURTHER RESEARCH}

Initial civilian student pilots have anxiety levels that need to be considered by instructors within an educational flight training organization. Pre-flight predictors of anxiety, such as insomnia, fatigue, urinary frequency, and apprehension, were significant predictors of high anxiety levels for initial student pilots. These high anxiety levels correlate significantly with physiological outcomes of nausea and airsickness.

Although anxiety and airsickness have correlated significantly in this study and others, airsickness appeared to be a factor in attrition from a flight-training aviation program, whereas anxiety has not appeared to have influenced pilot attrition rates. This finding rejects a hypothesis that increased anxiety precipitates pilot attrition.

The predictors of anxiety and the implications anxiety has on student learning may be helpful for improving flight education. Because higher degrees of anxiety tend to promote rote learning (Newble \& Entwistle, 1986), the problem-solving abilities desired in pilots may be lacking in anxiety-producing flight training situations. Future study is suggested to compare anxiety levels of pilots on solo flights, phase checks, and checkrides. .

Paul D. Lindseth is a Ph.D. candidate at the University of Michigan and an Assistant Professor of Aviation at the University of North Dakota's Center for Aerospace Sciences. His background includes both rotary and fixed-wing flight instruction in the Air Force and in higher education.

\section{REFERENCES}

Bagshaw, M., \& Stott, J. R. R. (1985). The desensitization of chronically motion sick aircrew in the Royal Air Force. Aviation, Space, and Environmental Medicine, 56, 1144-51.

Bucky, S. F., \& Spielberger, C. D. (1972). Effects of instruction on measures of state and trait anxiety in flight. Journal of Applied Psychology, 56, 275-276.

Bucky, S. F., \& Spielberger, C. D. (1973). State and trait anxiety in voluntary withdrawal of student naval aviators from flight training. Psychological Reports, 33, 351. 
Flight Anxiety: Predictors and Implications for Learning

Federal Aviation Administration. (1977). Aviation instructor's handbook. Washington, DC: U.S. Department of Transportation.

Fox, S., \& Arnon, I. (1988). Motion sickness and anxiety. Aviation, Space and Environmental Medicine, 59, 728-733.

Garcia-Otero, M., \& Teddlie, C. (1992). The effect of knowledge of learning styles on anxiety and clinical performance of nurse anesthesiology students. Journal of the American Association of Nurse Anesthetists, 60, 257-260.

Gupta, G. C. (1991). Student attrition: A challenge for allied health education. Journal of the American Medical Association, 266, 963-967.

Knowles, M. (1975). Self directed learning: A guide for learners and teachers. Chicago: Association Press/Follett.

Levitt, E. E. (1980). The psychology of anxiety (2nd ed.). Hillsborough, NJ: Lawrence Erlbaum.

Newble, D. I., \& Entwistle, N. J. (1986). Learning styles and approaches: Implications for medical education. Medical Education, 20, 162-175.

Seipp, B. (1991). Anxiety and academic performance: A meta-analysis of findings. Anxiety Research, 4, 27-41.

Strongin, T. S. (1987). A historical review of the fear of flying among aircrew. Aviation, Space, and Environmental Medicine, 58, 263-267.

Tooth, D., Tonge, K., \& McManus, I. C. (1989). Anxiety and study methods in preclinical students: Causal relation to examination performance. Medical Education, 23, 416-421.

Tucker, G. J., \& Reinhardt, R. F. (1967). Airsickness and anxiety. Aerospace Medicine, 38, 855-858.

Ward, M. J., \& Lindeman, C. A. (1982). Instruments for measuring nursing practice and other health care variables: Volume 1, 196-199. Boulder: Western Interstate Commission for Higher Education.

Zung, W. W. K. (1980). How normal is anxiety. Current Concepts, 10. Kalamazoo, MI: Upjohn. 